\title{
Passive Solar in the United States: 1976-1986
}

J. Douglas Balcomb

Los Alamos National Laboratory
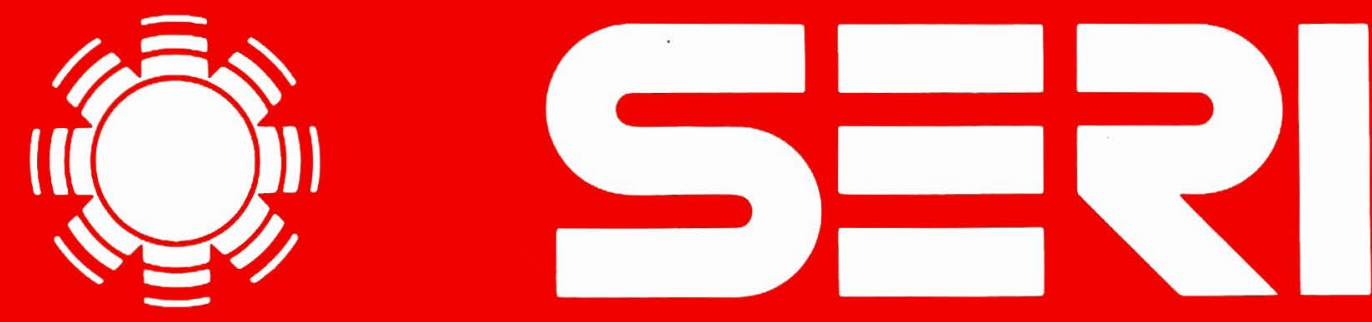

Solar Energy Research Institute A Division of Midwest Research Institute

1617 Cole Boulevard

Golden, Colorado 80401-3393

Operated for the

U.S. Department of Energy

under Contract No. DE-AC02-83CH10093 


\section{NOTICE}

This report was prepared as an account of work sponsored by the United States Government. Neither the United States nor the United States Department of Energy, nor any of their employees. nor any of their contractors, subcontractors, or their employees, makes any warranty, expressed or implied, or assumes any legal liability or responsibility for the accuracy, completeness or usefulness of any information, apparatus, product or process disclosed, or represents that its use would not infringe privately owned rights.

\section{Printed in the United States of America}

Available from:

National Technical Information Service

U.S. Department of Commerce

5285 Port Royal Road

Springfield, VA 22161

Price: Microfiche A01 Printed Copy AO2

Codes are used for pricing all publications. The code is determined by the number of pages in the pubiication. Information pertaining to the pricing codes can be found in the current issue of the following publications, which are generally available in most libraries: Energy Research Abstracts. (ERA): Government Reports Announcements and Index (GRA and 1); Scientific and Technical Abstract Reports !STAR): and publication. NTIS-PR-360 available irom NTIS at the above address. 
UC Categories: 59, 59a, 59c

DE87001136

\section{Passive Solar in the United States: 1976-1986}

J. Douglas Balcomb

Los Alamos National Laboratory

January 1987

Prepared under Task No. 3050.10

FTP No. 623

Solar Energy Research Institute

A Division of Midwest Research Institute

1617 Cole Boulevard

Golden, Colorado 80401-3393

Prepared for the

U.S. Department of Energy

Contract No. DE-AC02-83CH10093 


\section{SEPI禨}




\title{
PASSIVE SOLAR IN THE UNITED STATES: $1976-1986$
}

\author{
J. Douglas Balcomb \\ Distinguished Research Fellow \\ Solar Energy Research Institute* \\ 1617 Cole Blvd., Golden, Colorado 80401 USA
}

\begin{abstract}
A decade of experience in passive solar development in the United States is reviewed. More than 200,000 residential and 15,000 institutional and commercial passive solar buildings have been constructed since 1976. The evolution of the program through its peak in 1980 to the present is described. Methods of performance prediction and evaluation are discussed including analysis methods, design tools, test modules and monitored buildings. Results of the monitoring show excellent performance, generally in agreement with the analysis, for both residences and larger buildings. Passive practice is analyzed and problems are discussed. The current research program is described. Potential savings are estimated.
\end{abstract}

* On a two year leave of absence, until October 1987, from the Los Alamos National Laboratory, Los Alamos, New Mexico, 87545. 


\section{INTRODUCTION}

Since 1976 there has been a major effort to promote passive solar energy applications in the United States. Largely this has focused on passive solar heating of single family residences; however, there has also been work on multifamily and commercial buildings and also on natural cooling and on daylighting. It is estimated that there are now more than 200,000 residential and 15,000 commercial passive solar buildings in the United States; thus it is an accepted and proven technology (Renewable Energy Institute, 1986).

Detailed computer simulation models have bean used extensively to predict the performance of passive solar buildings. Design tools usable by architects have been developed by correlating the results of numerous computer simulations of different passive solar strategies in different climates. Design guidelines have evolved for balancing conservation strategies and passive solar strategies depending on climate and economics. Design competitions have been used effectively to promote the construction of many buildings throughout the country.

A major government program launched by the Department of Energy to quantify the performance of passive buildings resulted in the detailed monitoring of more than 100 residential and 22 commercial structures. In general the performance has been excellent and the occupants have been very satisfied.

The most important conclusion from this decade of work is that we have learned how to design, construct and operate buildings that use a fraction of the energy of conventional buildings, that provide a more comfortable and livable interior environment, and that cost little or no more to construct. 


\subsection{RECENT HISTORY OF PASSIVE SOLAR DEVELOPMENT}

Although there are historical and archaeological examples of the use of passive solar by native Americans, there were very few buildings which were consciously designed to utilize passive solar energy prior to the decade of the 1970's. Some direct gain buildings were constructed in the midwest in the 1930's and other isolated examples can also be found. A group of engineers at the Massachusetts Institute of Technology experimented with passive solar test rooms in 1946. Significantly, although they measured reasonable performance in the cloudy Boston climate, the group abandoned this line of research in favor of systems with solar collectors, pumps, and storage tanks, setting the stage for the future. Thus it was that active solar became the prime strategy promoted for development after the oil embargo triggered a major solar development program.

The first evidence of strong interest in passive solar appeared in 1976 at a passive solar conference held in Albuquerque, New Mexico. Annual national conferences have been held since that time with interest continuing to be very strong through 1982 and declining somewhat in the last few years as public concern over all energy issues has slackened.

Support for both research and commercialization of passive solar by government agencies lagged behind support for active solar by about four years; however, this situation has now reversed, with passive receiving the greatest emphasis, largely due to the good performance, low cost, ease of maintenance, and good acceptance of passive solar approaches by both building designers and the public.

Peak funding for passive solar occurred over the years 1979-81 during which the average annual expenditure on passive solar by the US Department of Energy averaged 29 million dollars per year (Renewable Energy Institute, 1986). This has now declined to about 8 million dollars per year for all of solar buildings research. During the peak period the emphasis was on commercialization activities such as information programs, design competitions, training programs, and surveys of consumer attitudes. These activities have been phased out totally so that the present program is almost entirely devoted to research.

A recent and very significant development is the realization that passive strategies can be very effective in institutional and commercial buildings. Usually the major passive sțrategy employed is daylighting, since these buildings are mostly used during the daytime. However, there is a natural synergy between daylighting and passive solar heating if the windows used for daylighting are south facing. Also it is possible to reduce cooling requirements since much of the cooling load is due to heat generated by artificial lights(Gordon et al., 1986). 


\subsection{PERFORMANCE EVALUATION}

\subsection{Passive Solar Performance}

The net energy benefit of adding passive solar strategies varies with climate, system type, system design, and system size. When the system and building conservation parameters are optimized for the climate, the net benefit (defined as a reduction in backup heat compared to a perfectly insulated wall) is usually in the range of 50,000 to 100,000 Btu/year per sq. $\mathrm{ft}$. of aperture (150 to $300 \mathrm{kWh} /$ year per sq. meter of aperture). Added cost for residential construction is usually in the range of 5 to $15 \$ /$ sq. ft. of aperture (50 to $150 \$ / \mathrm{sq} . \mathrm{m}$. of aperture) and backup heat cost is in the range of .02 to $.07 \$ / \mathrm{kWh}$. The added cost associated with the passive solar features is usually 4 to 8 percent of the total cost of construction of a residence and the payback time is usually within 5 to 10 years.

\subsection{Performance Analysis}

Performance estimation is frequently done by scientists and engineers using mainframe computer programs for hour-by-hour simulation analysis. This is normally for the purpose of research or systems analysis rather than for the design of a particular building.

Two main mathematical approaches have been used to describe the dynamic behavior of buildings. The most straightforward is the use of thermal networks in which the flow of heat from point to point in the building and the storage of heat in massive elements are characterized by a set of ordinary differential equations. The other standard approach is to use weighting functions in which the time response on one side of a wall is described as a convolution of the inputs on both sides. Harmonic analysis is a third technique which is used less often. Each method has its advantages and disadvantages and strong advocates.

\subsection{Design Tools}

Design of most passive buildings is done without any analysis simply by emulating other buildings, by intuition or by using simple rules of thumb. When an analysis is made, the most widely used design tools are simplified monthly methods based on correlating the results of the numerous computer simulations. The most common of these is the Solar Load Ratio (SLR) method (in which the correlation parameter is the ratio of solar gain to building load) (Balcomb, et al., 1982 and Balcomb, et al., 1984). This analysis can be done by hand or with the aid of the one of the numerous microcomputer programs based on the method.

A very effective design tool, targeted specifically for builders, is a set of builder guidelines, written for a specific locality. This package, which has been demonstrated in several places including New Mexico and North Carolina, contains three parts: 1) target levels for building loss coefficient, auxiliary heat, thermal comfort (expressed as a winter temperature swing), and auxiliary cooling; 2) guidelines. which will help the designer meet these target levels; and 3) simple fill-in-the-blank worksheets for calculating the above values for comparison with the target levels. The approach is nonprescriptive; it allows for a wide variation in the design of the building from superinsulated at one extreme to explicitly passive solar at the other extreme. 
A trend is now developing for simulation programs which take full advantage of the increased computing power of the current generation of microcomputers. These are normally used in the design of larger structures such as institutional and commercial buildings in which the energy issues are much more complex than for residential buildings. We can foresee that computer-assisted design (CAD) techniques, now commonly used for drafting, will be expanded to include energy analysis.

\subsection{Test Modules}

Test modules, as described by Moore (1982), have been built in three general sizes: small test boxes, usually about a $3 \mathrm{ft}$. cube ( 1 meter cube); test rooms, usually about $40 \mathrm{sq}$. $\mathrm{ft}$. ( 4 sq. m.) in area; and unoccupied larger test buildings. Each of these have proved to be very valuable for different types of tests and have also been found to be excellent for teaching college students the principles of monitoring, data evaluation, and comparing theory and experiment.

These test modules have played an important role in passive research. Quite a large number of modules have been built at several institutions to obtain data under carefully controlled conditions. The units serve one or more of the following purposes:

(1) Direct side-by-side comparison of competing strategies.

(2) Obtaining data for the validation of computer programs.

(3) Component testing under realistic conditions.

Test modules are sometimes operated free-running, that is, without auxiliary heating or cooling. More commonly, they are operated with a thermostatically controlled inside environment. This allows a more direct comparison of the net energy benefit of the units and yields a more realistic operating profile.

\subsection{Monitored Buildings}

Results of a large-scale program conducted by the US DOE indicate good performance of actual occupied buildings monitored over periods of one or more years using 20 or more sensors connected to hour-by-hour recording equipment. Subsequent computer analysis of the data from 70 homes in various climates shows (SERI, 1984):

- These passive solar homes use $70 \%$ less auxiliary heat than conventional homes, with the average solar contribution being $37 \%$ of the total heating load or $55 \%$ of the net heating load (total minus internal gains from people, light, and appliances).

- Between the various systems employed (direct gain, Trombe walls, and sun spaces), there was no noticeable difference in performance. In fact, many of the houses used combinations of two or more solar options to good advantage.

- Building heat loss coefficients per unit floor area in the range of 4 to $6 \mathrm{Btu} /{ }^{\circ} \mathrm{F}$-day-sq. ft. (0.8 to $1.5 \mathrm{~W} / \mathrm{C}$-sq.m.) are routinely achieved, underlining the importance of good conservation practice. Auxiliary heating requirements as low as 1 to $2 \mathrm{Btu} /{ }^{\circ} \mathrm{F}$-day-sq. ft., 0.25 to $0.5 \mathrm{~W} / \mathrm{C}$-sq.m. are demonstrated in sunny climates and values of 1.5 times these levels are achieved routinely in all climates.

- Solar fractions of $50 \%$ or more are often achieved; however in a few cases the solar performance is illusory because losses from the solar elements exceed their solar gains. 
- Movable insulation systems intended to reduce heat losses at night have generally not worked out well. In fact, it is questionable whether they saved any energy at all. This is certainly due, at least in part, to the fact that there is no tradition of outside rolldown shutters in the U.S. Most of the products which were used were of recent design, most were designed to fit inside the window rather than outside, many were not mechanically reliable, and the occupants, not being accustomed to the daily operation of such systems, tended to resent the extra effort involved.

- Comparisons were made of the monitored results with performance estimates based on the actual weather, solar, and inside temperature conditions. Deming and Duffy (1986) found that both the SLR and the unutilizability method estimates match the auxiliary heat used quite well on average (within $4 \%$ for SLR and $13 \%$ for unutilizability). However, for a given passive solar building, the predictions can vary significantly from measurements (the root-mean-square difference is about 30\% for both methods). Much of the discrepancy for individual houses appears to be due to uncertainties in the measured heat loss coefficient and not necessarily in the passive solar prediction.

- Occupants of the houses are very satisfied with them.

Analysis of the data from 21 monitored institutional and commercial buildings by Gordon, et al. (1986) shows:

- Overall energy savings, compared to "base-case" buildings of the same size and function in the same location, are about $47 \%$. Lighting energy is reduced $68 \%$, heating energy is reduced $44 \%$ and cooling energy is reduced $68 \%$. Only the small category of "other" energy (mostly energy to run equipment and fans) is increased.

- Daylighting was a major design strategy in all of the buildings. Post-occupancy evaluation indicates that the most common reaction is a strong appreciation of the quality of the inside environment, especially the light.

- Usage of the buildings by people is higher than had been planned. This partly explains why the savings in heating energy is not always quite as large as predicted.

- The construction cost of the buildings was nearly identical to that estimated for the base-case buildings. The added cost of the solar options was partially offset by reductions in the cost of equipment.

- Peak demand for electricity was substantially reduced compared to the base-case buildings.

- Problems with controls were experienced in some of the buildings. Most often this was due to the thermostat having been set back too far at night or the heating system having been started up too late in the morning with the result that the building might be uncomfortably cool on early winter mornings.

- The cost of designing the buildings was greater than for conventional buildings due to the extra effort of optimizing the interrelationship of the passive solar and other systems. This probably will be less noticeable in time as daylighting and passive solar become more routine and as better design tools become available.

- The important lesson learned which has been stressed by Ternoey, et al., (1984) is that the key to achieving good overall energy performance lies in the integration of daylighting, passive solar heating, and natural cooling into the overall design. 


\subsection{PASSIVE PRACTICE}

In less than a decade "passive solar" has become part of the vocabulary of building designers, buyers, realtors, financers, and researchers. Coined in the early 1970's, the word passive was intended to emphasize an alternative to the then-popular active solar technique. Because it employs conventional building materials and because the basic concepts are easily understandable, passive solar has found ready acceptance among designers and builders. The term passive solar is now used to include the strategies of passive solar heating, natural cooling, and daylighting.

By itself, passive solar does not make a good building, as many of the early examples demonstrate. Many other factors, such as sound architectural design and good siting, must also be correct. However, passive solar provides visible testimony that good energy design has been a priority. Some of the factors which have proved to be effective, considering both technical and marketing issues, are discussed below.

\subsection{Residential Buildings}

\subsubsection{All solar subdivisions}

Purchase of a solar building located among non-solar buildings requires a conviction unlikely in any but an early innovator. By contrast, clusters of passive solar buildings signal a trend and give evidence of a degree of societal acceptance necessary to most people undertaking a large financial obligation. Rather than feeling innovative, the buyer becomes part of the trend along with his neighbors.

\subsubsection{Site planning and development}

With a little forethought, good solar access can be planned into a development with no loss in density. Zoning restrictions can be adopted which guarantee continued solar access to every building.

\subsubsection{Sun spaces}

Sun spaces have become extremely popular in the United States, both for new construction and for retrofit of existing buildings. They provide a sunny living area and are often, but not always, used for growing plants. Properly designed, they require no backup heat, they furnish as much passive solar heat to the house as the same glazed area of direct gain or Trombe wall, and they do not overheat in summer.

\subsubsection{Balanced conservation and passive solar}

The economic tradeoff between more insulation and more solar gains leads to an easily derived optimum design solution which is climate dependent. However the curve is fairly flat so that near-optimum performance can be realized over a reasonably wide range of design choices. But in all cases good insulation practices and low infiltration are essential. If this is not done, the required solar area will be too large, thermal mass requirements for adequate heat storage will be too great, and control will be difficult. 


\subsubsection{Good thermal comfort}

Thermal comfort requires stable interior temperatures which means that the building should have small temperature swings under free-running conditions. This requires adequate thermal mass for heat storage, a proper relationship between the location of solar gains and heat storage, and effective thermal distribution. Without these essentials, the building will not create the type of internal environment necessary to ensure the adoption of passive solar buildings on a large scale.

\subsubsection{High quality of construction}

By adherence to the principles outlined above, the designer will have already integrated good thermal quality into the building. It is only consistent to follow this up with use of good materials and high quality of construction to ensure that the building will be-viable over the long term.

\subsection{Institutional and Commercial Buildings}

\subsubsection{Daylighting}

Good daylighting design, which was well understood and practiced before the advent of the fluorescent lamp, is now coming back. The use of natural light in buildings is not only essential to good architecture but it makes good energy sense. By use of windows, light shelves, clerestories, roof monitors, and atria, daylight can be brought into most rooms of most buildings. Use of natural light not only reduces the need for artificial lighting energy but, since natural light contains more light per unit of heat, it reduces cooling loads produced by the lights. Good daylighting design avoids direct-beam sun penetration into the building. Instead, sunlight is diffused from strategically placed louvers or baffles which are painted eggshell white to achieve colorless soft lighting. Glare is avoided by placing all such diffusing surfaces and diffusing glazing well above eye level.

By orienting windows used for daylighting to the south, both heating and cooling loads are reduced. Artificial lighting systems and their controls must be well integrated with the daylighting or energy may not be saved.

\subsubsection{Atria}

The atrium has become a very popular design element for architects, adding character and vitality to the building. Atria are very complex both thermally and optically and are not well understood. They can have either a positive or negative energy impact on the building depending on the design.

\subsubsection{Balancing}

Thermal balancing of the building must be done on a space-by-space basis and also on a time-of-day basis considering orientation, patterns of internal heat generation, and occupancy. Mismatches between the availability of natural energies and the energy needs of various spaces may require transporting heat from space to space. However, this should be minimized because it invariably increases complexity and cost. 


\subsubsection{Regionalism}

There is now a growing trend toward regionalism in architecture. This fits in well with passive solar design because building types which evolved before this century were often based on accommodation to the climate. This is particularly evident in the southeast United States where several traditional housing types have been identified which make effective use of sun protection and natural ventilation. Often, it is the same designers who are concerned with historical preservation, use of traditional building styles and techniques (updated to use modern materials and methods) and passive solar design. We can hope that the current total emphasis on stylistic issues will gradually shift toward a return to a functionalism which pervades the entire building design. 


\subsection{PROBLEMS}

Passive solar development has not been without its problems, two of which are discussed below.

\subsection{Overheating}

Overheating by the sun can occur in winter or in summer, but these are usually due to different design errors. Winter overheating can occur if the south glazing is oversized or there is insufficient thermal storage mass for the amount of direct gain. Good design practice is to limit the collecting area for solar gain to a value which would result in an average inside temperature no greater than $72^{\circ} \mathrm{F}\left(22^{\circ} \mathrm{C}\right)$ on a clear January day. Thermal storage should be sized to limit the inside temperature swing to no more than $9 \quad\left(5^{\circ} \mathrm{C}\right)$ on a clear winter day. In any case the area of direct gain should not be greater than about $13 \%$ of the floor area of the building or problems of glare, ultraviolet fading of materials, and loss of privacy will result. If solar glazing area greater than this amount is desired, then an indirect system, such as a Trombe wall or sun space should be used.

Summer overheating can usually be traced to excessive east, west, or horizontal glass in the design. This is a common problem in sun spaces. The remedy is to emphasize southfacing glass and avoid large glazing areas on any other orientation. If skylights in houses or overhead glazing in sun spaces are used, they should be covered in the summer. Proper natural ventilation is also essential to avoid high summer inside temperatures.

\subsection{Perception}

This is listed as a problem because understanding of passive solar by the public, by the building industry and by design professionals is not nearly as good as it could be. The excellent performance results which have been obtained are not widely recognized nor is a need for saving energy seen as a priority. Most people are very conservative about their homes and there is a great reluctance to make any changes in style or appearance.

There are two solutions to these problems of perception. The first is public education. Publicizing effective and attractive passive solar buildings can alleviate many of the concerns. Exotic concepts, such as underground buildings, or extremely modernistic designs are likely to meet resistance and should be avoided. Certain building types, such as schools and libraries, provide-excellent opportunities for passive solar and daylighting and should be used as demonstrations. Experimentation on new concepts should be confined to the laboratory; only tried and proven systems should be put into buildings which are to be used because errors are always publicized and are very harmful to the image of passive solar.

The second solution is to establish a good program of educating architects both within colleges of architecture and in short courses for practicing architects. Education of builders can best be done through builder guideline packages and seminars. 


\subsection{FUTURE RESEARCH DIRECTIONS}

Currently, government funding for passive solar is primarily for research with emphasis on systems analysis and on new products and materials. The objective of the research is both to improve performance and to achieve greater penetration of passive solar techniques into the marketplace.

Systems analysis is aimed at a better understanding of how passive systems work in buildings, determining what are the most effective directions for research, and on developing design tools. Daylighting is receiving priority in institutional and commercial buildings. Natural cooling continues to be investigated although it has thus far proved to be difficult to implement and to quantify. New design tools are being developed. Methods of maximizing the information which can be derived from short-term monitoring are being investigated.

New products and materials research emphasizes work on improved glazings and other aperture materials with three objectives; reduced heat losses, improved transmittance, and greater controllability. Coating on glazings which have a low emittence in the infrared are now in common use and efforts are being made to improve their performance. Coatings with optically switchable properties are being investigated using thermochromic, photochromic, or electrochromic phenomena. Aerogels and evacuated glazings are being investigated with the object of reducing heat transmission coefficients to as low as $0.1 \mathrm{Btu} /{ }^{\circ} \mathrm{F}$-h-sq. $\mathrm{ft}$. $\left(0.6 \mathrm{~W} /{ }^{\circ} \mathrm{C}\right.$-sq.m. $)$ while maintaining at least $50 \%$ optical transmittance. Work is also being done in improving thermal storage capacity of building materials by impregnating them with a solid-solid phase change material. 


\subsection{THE 64 BILLION DOLLAR QUESTION}

Residential buildings in the U.S. consume approximately 15 quads of energy annually $\left(4.4 \times 10^{12} \mathrm{kWh}\right)$ and commercial and institutional buildings consume 10 quads $\left(2.9 \times 10^{12} \mathrm{kWh}\right)$. The sum of these represents $36 \%$ of U.S. energy consumption at an annual cost of $\$ 160$ billion per year. Of these 25 quads, electricity represents $62 \%$ while natural gas and oil represent $36 \%$ and $10 \%$ respectively. The major uses are space heating ( 9.7 quads), lighting (3.7 quads), cooling/air conditioning (3.7 quads), hot water ( 3 quads) and appliances/other ( 5.4 quads).

The potential for displacing these energy requirements by use of conservation and passive solar strategies depends on several factors: the potential savings for each building, the fraction of new buildings which use these strategies coupled with the rate of new building construction, and the rate of retrofit of existing buildings. Using reasonable estimates for the maximum credible market capture for these strategies, one can predict an annual savings of perhaps 10 quads per year $\left(2.9 \times 10^{12} \mathrm{kWh}\right)$ in year 2010 , corresponding to an annual savings of at least $\$ 64$ billion, in current dollars. It is important to note that this savings would accrue each year at no additional expenditure of capital. This enormous potential should easily justify a much greater emphasis being placed on these strategies; however, this potential will probably not be realized if current attitudes continue.

In addition to building owners there would be many beneficiaries to achieving the full potential of conservation and passive solar strategies. Our natural security would be enhanced because of reduced dependence on energy imports and the reduced need for new electric generating capacity, freeing vast capital resources to be invested in modernizing U.S. industry. Environmental quality would be enhanced as a result of the reduced level of extracting and burning conventional fuels which pollute both the air and water. The private building industry and their product suppliers would benefit due to an increased level of construction, especially for retrofit of existing buildings. Building designers would benefit because of a greatly increased need for their services. Unemployment would be reduced in response to increased demand for local construction skills. 


\subsection{CONCLUSIONS}

Passive solar development has been partially successful in the U.S. but current public complacency about energy issues in general has greatly slowed penetration into the market. This complacency is clearly associated with decreases in oil prices even though the cost of energy for building heating, cooling and lighting is no lower than it was in 1977-79 when interest was increasing.

We have learned how to build much better buildings and to use passive systems to effectively harness environmental energies. The challenge now is to maintain the momentum. The best way I see to do this is to emphasize the fact that passive solar leads to a higher quality interior environment. The energy issue has already received ample attention. Now we should stress the good thermal comfort possible with passive heating and cooling and the delightful character of natural light. Since a major purpose of the built environment is to provide shelter and comfort, we should let it be known that passive strategies can do this very well indeed - and can do it reliably and economically. 


\subsection{REFERENCES}

Balcomb, J. D., R. W. Jones, R. D. McFarland, and W. O. Wray, 1984. Passive Solar Heating Analysis. Atlanta, GA: ASHRAE.

Balcomb, J. Douglas, 1984. Passive Solar Research and Practice. Energy and Buildings, 7. Elsevier-Sequoia; 281-295.

Balcomb, J. D., R. W. Jones, R. D. McFarland, and W. O. Wray, 1982. Performance Analysis of Passively Heated Buildings: Expanding the SLR Method. Passive Solar Journal 1 (2): $67-90$.

Deming, G. and J. J. Duffy, 1986. Un-Utilizability Design Tool Predictions Compared to Auxiliary measurements of Passive Solar Residences. In Proc. of the 198611 th National Passive Solar Conf., June 7-11, 1986, Boulder CO: ASES: Pp. 88-93.

Gordon, H. T., P. R. Rittleman, J. Estoque, G. K. Hart, and M. Kantrowitz, 1986. Passive Solar Energy for Non-Residential Buildings. Advances in Solar Energy, 3. NYC: Plenum Press.

Moore, F., 1982. Passive Solar Test Modules. Passive Solar Journal 1 (2): 91-108.

Renewable Energy Institute, 1986. Annual Energy Technology Review, Progress Through 1984. 1001 Connecticut Ave., Suite 719, Wash. D. C. 20036.

Ternoey, S., L. Bickel, C. Robbins, R. Busch, and K. McCord, 1985. The Design of Energy Responsive Commercial Buildings. NYC: Wiley-Interscience. 